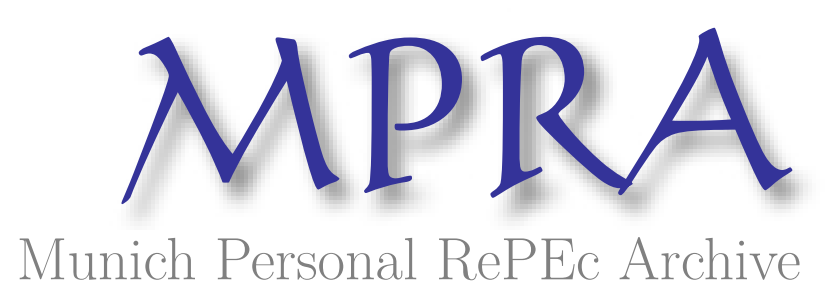

\title{
Should the Government Protect its Basic Research?
}

Cozzi, Guido and Galli, Silvia

June 2017

Online at https://mpra.ub.uni-muenchen.de/79622/

MPRA Paper No. 79622, posted 09 Jun 2017 19:39 UTC 


\title{
Should the Government Protect its Basic Research?
}

\author{
Guido Cozzi and Silvia Galli
}

\begin{abstract}
Basic research is mainly performed publicly. Yet in the US public research findings were not patentable until 1980, and in other countries are not yet patentable. Patentability renders public research more directed, with less potential waste, but it also restricts private applied research. This paper shows, by means of a multi-stage Schumpeterian growth model, that in the long run the first effect is bound to dominate.
\end{abstract}

JEL classification: O30, O40.

Keywords: R\&D and Growth; Sequential Innovation; Public R\&D; Patent Laws.

Corresponding author: Guido Cozzi, Department of Economics, University of St. Gallen, Address: Guido Cozzi, FGN-HSG, Büro 34-002, Varnbüelstrasse 19, 9000 St.

Gallen, Switzerland,Phone: +41 71224 2399, fax: +41 (0) 7122428 87, email: guido.cozzi@unisg.ch

Silvia Galli, Department of Economics, University of St. Gallen, Address: Silvia Galli, FGN-HSG, Büro 34-302, Varnbüelstrasse 19, 9000 St. Gallen, Switzerland, Phone: +41 71224 3086, fax: +41 (0) 7122428 87, email: silvia.galli@unisg.ch 


\section{Introduction}

After the second world war, universities and public laboratories have always been the main performers of basic R\&D in the United States and in Europe. The year 1980 marked an important turning point in US patentability requirements with the Bayh-Dole Act, which facilitated universities in patenting innovations ${ }^{1}$. The incentives for academic researchers in the public sector to explore potentially profitable avenues have since then increased, but at the cost of more restrictions for applied R\&D firms, which previously free rode on a flow of unprotected fundamental ideas. In this paper we show, by use of a novel theoretical model, that the first effect will dominate in the longer run.

The paper contributes to a still scarce but expanding R\&D-driven growth literature on basic research policy, such as Aghion and Howitt (1996), Gersbach et al. (2008, 2010, 2013, and 2015), Howitt (2013), Spinesi (2012 and 2013), Gersbach and Schneider (2015), and Akcigit et al. (2016). However, unlike these papers, we consider basic research within a creative destruction Schumpeterian growth model extended to incorporate the distinction between basic and applied ideas in the product innovation process. ${ }^{2}$

The rest of this paper is organized as follows. Section 2 sets up the main model we use to compare the two institutional scenarios. Section 2.1 applies this new framework to a stylized pre-1980 US scenario: basic research findings are conceived in public institutions and put into the public domain, triggering patent races by freely entering perfectly competitive private $R \& D$ firms aiming at inventing a better quality product. Section 2.2 studies a stylized Bayh-Dole Act scenario, where basic R\&D achievements of public institutions are patented and, afterwards, developed into tradable applications by profit maximizing patent holders. In Section 2.3 we prove our main result. Section 3 concludes with some comments.

\footnotetext{
${ }^{1}$ Prior to the Bayh-Dole act, the public co-funding of research - which is now pervasive in the academia - posed a serious legal problem to the patentability of basic research.

${ }^{2}$ Unlike Cozzi and Galli (2009 and 2014), which also use a multistage Schumpeterian approach, we focus on the long-term effects of the patentability of public research results.
} 


\section{The Model}

Consider an economy as in Grossman and Helpman (1991), with a continuum of differentiated consumption good sectors $\omega \in[0,1]$ with corresponding differentiated R\&D sectors. In each sector, a monopolistically competitive patent holder of the cutting edge quality good produces differentiated consumption goods, by combining skilled and unskilled labour, until replaced by a better quality product monopolist. Product improvements occur in each industry in continuous time $t$. When the state-of-the-art quality product in an industry $\omega \in[0,1]$ is $j_{t}(\omega) \in N, \mathrm{R} \& \mathrm{D}$ firms compete in order to learn how to produce the $j_{t}(\omega)+1$ st quality product. However, unlike Grossman and Helpman (1991), we assume that an intermediate basic research idea is necessary in order to start applied R\&D looking for the new product. ${ }^{3}$ Both basic and applied research employ only skilled labour. Hence in our framework, basic research can be targeted to a specific industry and it depends on the existence of an already commercialized innovation in the sector. ${ }^{4}$

Consequently, at any instant we can partition the set of industries $[0,1]$ into two subsets: industries $\omega \in A_{0}$, with measure $m_{t}\left(A_{0}\right)$, still lacking a useful basic research result needed for applied R\&D to start; and industries $\omega \in A_{1}$, of measure $1-m_{t}\left(A_{0}\right)$, in which a basic idea is present, useful for applied R\&D to complete the next quality product. Let $n_{B}(\omega, t)$, indicate the basic research employment of a sector $\omega \in A_{0}$, and $n_{A}\left(\omega^{\prime}, t\right)$ applied research employment in a sector $\omega^{\prime} \in A_{1}$ at date $t$.

We assume that researcher's Poisson process probability intensity to succeed in inventing a basic research idea is $\lambda>0$, whereas the probability of finding the corresponding application is $\frac{g\left(n_{A}(\omega, t)\right)}{n_{A}(\omega, t)}$, where $g(0)=0$, $g^{\prime}>0>g^{\prime \prime}, \lim _{x \rightarrow 0} g^{\prime}(x)=\infty, \lim _{x \rightarrow \infty} g^{\prime}(x)=0$. These Inada conditions guarantee, with no loss of generality, an interior solution (see Scotchmer, 2004), and incorporate an intra-sectoral congestion effect in applied R\&D, capturing "stepping on toes" (Jones and Williams, 1998 and 2000).

In symmetric equilibria we can write: $n_{B}(\omega, t) \equiv n_{B}(t)$ and $n_{A}(\omega, t) \equiv$ $n_{A}(t)$. Hence the probability per unit time of the arrival of a basic research idea at date $t$ in a sector $\omega \in A_{0}$ is $n_{B}(t) \lambda$, while the probability per unit time of the arrival of a better quality product in a sector $\omega \in A_{1}$ is $g\left(n_{A}(t)\right)$.

\footnotetext{
${ }^{3}$ See Cozzi and Galli (2014) for a similar framework, but with private basic research only.

${ }^{4}$ This captures Nelson's (2006) idea of R\&D as a two-way feedback process, in which basic research's theorizing is inspired by applied research results.
} 
The wage of the unskilled labour is the numeraire, and the skilled labour wage is $w$. The aggregate supply of skilled labour is constant and denoted $L>0$.

In our symmetric equilibria, the per-capita mass of skilled labour employed in each manufacturing sector $\omega \in[0,1]$ at time $t$, labeled $x_{t}$ is a decreasing function of the skilled wage. i.e. $x_{t}=x(w(t))$, as in the usual Schumpeterian models ${ }^{5}$.

As for example Aghion and Howitt (1992) and Cozzi and Galli (2014), we will assume: $x(0)>L, x^{\prime}>0>x^{\prime \prime}, \lim _{w \rightarrow 0} x^{\prime}(w)=\infty$, and $\lim _{w \rightarrow \infty} x^{\prime}(w)=$ 0 .

\subsection{Unpatentable Public Research}

Let us assume that the public researchers, unguided by the profit motive, have no incentive in allocating their R\&D efforts in the $m\left(A_{0}\right)$ sectors where they are needed by the applied R\&D firms. Rather, lacking additional motivation, they are distributed over the sector space $[0,1]$ according to a uniform distribution. This untargetness is the only non-market inefficiency, directly stemming from the absence of a profit seeking motive.

We denote $\bar{L}_{G} \in[0, L]$ the exogenously given amount of skilled workers employed in the public basic research institutions, assumed funded by lump sum taxes on consumers.

Being $\bar{L}_{G}$ uniformly spread over the product space, it also denotes the per sector amount of basic research. That is:

$$
n_{B}=\bar{L}_{G}
$$

Therefore the probability that in any given sector $\omega$ temporarily in $A_{0}$ a useful basic idea will appear is $\bar{L}_{G} \lambda$, whereas the probability that in a sector $\omega$ temporarily in $A_{1}$ an existing intermediate idea generates a new marketable product is $g\left(n_{A}\right)$. Basic research labour researching in a sector $\omega \in A_{1}$ is not producing any useful research idea, but a redundant duplication of the existing one ${ }^{6}$.

\footnotetext{
${ }^{5}$ We borrow the household and the manufacturing set up from Cozzi and Galli (2014), which we do not repeat to save on redundant space.

${ }^{6}$ Being costly to find, this equally useful idea is likely derived in a novel way, and thereby still effective to enhance the inventor's academic CV.
} 
Let us define $v_{L}^{0}(t)$ as the stock market value of a monopolistic firm producing the top quality product in a sector $\omega \in A_{0}$, and $v_{L}^{1}(t)$ as the value of a monopolistic firm producing the top quality product in a sector $\omega \in A_{1}$. These two types of quality leaders both earn the same profit flow, $\pi(w(t))$ non-increasing in skilled wage. In sectors that are currently of type $A_{0}$ the applied R\&D firms cannot enter because there is no basic idea to be exploited: they shall wait until the public researchers invent one, causing that sector to switch into $A_{1}$. Instead, in an $A_{1}$ sector applied $\mathrm{R} \& \mathrm{D}$ firms hire skilled workers in order to complete the freely available basic idea. Since there is free entry into applied research, the R\&D firm's expected profits are dissipated. We drop time indexes from here on and we only focus on the steady state, in which - after defining $r$ as the relevant steady state interest rate $^{7}$ - the following free entry condition and stock market arbitrage equations hold:

$$
\begin{aligned}
w & =\frac{g\left(n_{A}\right)}{n_{A}} v_{L}^{0} \\
r v_{L}^{0} & =\pi(w)-\lambda \bar{L}_{G}\left(v_{L}^{0}-v_{L}^{1}\right) \\
r v_{L}^{1} & =\pi(w)-g\left(n_{A}\right) v_{L}^{1} .
\end{aligned}
$$

In the stationary distribution the flow of industries entering the $A_{0}$ group must equal the flow of industries entering the $A_{1}$ group. Hence:

$$
\left(1-m\left(A_{0}\right)\right) g\left(n_{A}\right)=m\left(A_{0}\right) \lambda \bar{L}_{G} .
$$

The skilled labour market clearing condition ${ }^{8}$ is:

$$
L=x(w)+n_{B}+\left(1-m\left(A_{0}\right)\right) n_{A} .
$$

Hence in this section we have six independent equations which allow us to uniquely solve for the six endogenous variables $w, n_{B}, n_{A}, v_{L}^{0}, v_{L}^{1}$, and $m\left(A_{0}\right)$.

\subsection{Bayh-Dole Act}

Unlike the previous section, we here model a post-Bayh-Dole Act US scenario: as a basic idea is invented in an $A_{0}$ sector, it gets protected by a patent with infinite legal life.

\footnotetext{
${ }^{7}$ Equal to the subjective rate of time preference in this class of models (see Cozzi and Galli, 2014).

${ }^{8}$ Since unskilled labour is only in manufacturing, we do not need to spell it out.
} 
Let $v_{A}$, denote the present expected value of a basic idea patent holder, operating an applied R\&D firm in an $A_{1}$ industry and aiming at becoming the new quality leader. Such a firm will optimally choose to hire an amount $n_{A}^{*}$ of skilled research labour to maximize the difference between its expected gains from completing its own basic idea - probability of inventing, $g\left(n_{A}\right)$, times the net gain from inventing the final product, $\left(v_{L}^{0}-v_{A}\right)$ - and the implied labour cost $w n_{A}$. Its first order conditions is:

$$
g^{\prime}\left(n_{A}^{*}\right)\left(v_{L}^{0}-v_{A}\right)=w .
$$

Costless arbitraging between risk free loans and firms' equities implies that at each instant the following arbitrage equations must hold in equilibrium:

$$
\begin{aligned}
& r v_{A}=g\left(n_{A}^{*}\right)\left(v_{L}^{0}-v_{A}\right)-w n_{A}^{*} \\
& r v_{L}^{0}=\pi-\lambda n_{B}\left(v_{L}^{0}-v_{L}^{1}\right) \\
& r v_{L}^{1}=\pi-g\left(n_{A}^{*}\right) v_{L}^{1}
\end{aligned}
$$

Notice that now in equation (4b), the partial obsolescence of a monopolist in $A_{0}$ is stronger because $\bar{L}_{G}$ gets spread over a smaller set of industries, of measure $m\left(A_{0}\right)$. In fact, unlike in the previous section where public researchers diluted their labour over the entire product space and waisted $\left(1-m\left(A_{0}\right)\right)$ of their efforts, here basic researchers target their activity only in the $A_{0}$ sectors. That is:

$$
n_{B}=\frac{\bar{L}_{G}}{m\left(A_{0}\right)}
$$

The steady state industrial dynamics of this economy is hence described by

$$
\left(1-m\left(A_{0}\right)\right) g\left(n_{A}^{*}\right)=\lambda \bar{L}_{G} \cdot
$$

Notice that unlike the previous equation (2), in eq. (5) the aggregate flow of new basic discoveries is $m\left(A_{0}\right) \frac{\lambda \bar{L}_{G}}{m\left(A_{0}\right)}=\lambda \bar{L}_{G}$.

The labour market clearing condition is:

$$
L=x(w)+m\left(A_{0}\right) n_{B}+\left(1-m\left(A_{0}\right)\right) n_{A}^{*} .
$$

Hence we have seven independent equations which allow to uniquely solve for the seven endogenous variables $w, n_{A}^{*}, n_{B}, v_{A}, v_{L}^{0}, v_{L}^{1}$, and $m\left(A_{0}\right)$. 


\subsection{Comparing the two Regimes}

Having set up the two economies, we can prove the following:

Proposition 1 The post-Bay-Dole act steady state equilibrium is characterized by more innovations than the steady state equilibrium in which public research institutions cannot patent basic discoveries.

Proof. In the unpatentable research case, we know from eq. (2) that the steady state equilibrium innovation rate is $m\left(A_{0}\right) \lambda \bar{L}_{G}$. Since $\lambda \bar{L}_{G}>0$, eq. (2) also implies that $m\left(A_{0}\right)<1$. In the Bayh-Dole act case, we know from eq. (5) that the steady state equilibrium innovation rate is $\lambda \bar{L}_{G}$, which is higher than $m\left(A_{0}\right) \lambda \bar{L}_{G}$ - where $m\left(A_{0}\right)$ here comes from the Bayh-Dole act system of equations. Therefore the statement follows.

Remark. The intuition behind this result is that when basic research is not wasted in $1-m\left(A_{0}\right)$ redundant research lines more scientific results will flow into applied R\&D. This dilutes applied R\&D labour on more industries, thereby increasing the marginal benefit of each industry's applied R\&D. Profit maximizing applied R\&D firms will therefore attract enough labour from the manufacturing sector to complete them. Notice that this occurs despite restricted entry to applied R\&D generated by patent barriers.

\section{Final Remarks}

We have proved that allowing the patentability of public basic research outcomes increases the long-run innovation rate of an economy, despite restricting entry into applied R\&D. This result suggests that the 1980's US policy switch to patentable public research results could have been not only good for the finances of the public universities and laboratories - now benefiting from patent royalties - but also for innovation and growth. This result could be useful for discussing a more pro-growth and financially sustainable research policy in several countries such as, for example, the European countries, Canada (Howitt, 2013), and Japan. 


\section{Bibliography}

Akcigit, U., Hanley, D. and Serrano-Velarde, N., (2016). "Back to Basics: Basic Research Spillovers, Innovation Policy and Growth," CEPR Discussion Papers 11707.

Aghion, P. and Howitt, P. (1992), "A Model of Growth through Creative Destruction", Econometrica 60 (2), pp. 323-351.

Aghion, P. and Howitt, P. (1996), "Research and Development in the Growth Process", Journal of Economic Growth, vol.1, pag 13-25.

Cozzi, G. and Galli, S. (2014). "Sequential R\&D and blocking patents in the dynamics of growth," Journal of Economic Growth, vol. 19(2), June, pp. 183-219.

Gersbach, H., M. Schneider, and O. Schneller, (2008), "On the Design of Basic-Research Policy," CER-ETH Economics working paper series 08/79.

Gersbach, H., M. Schneider, and O. Schneller, (2010), "Optimal Mix of Applied and Basic Research, Distance to Frontier, and Openness," CEPR Discussion Papers 7795, C.E.P.R. Discussion Papers.

Gersbach, H., M. Schneider, and O. Schneller, (2013), "Basic Research, Openness, and Convergence," Journal of Economic Growth, Springer, vol. 18(1), March, pp. 33-68.

Gersbach, H. and Schneider, M. T., (2015). "On the global supply of basic research," Journal of Monetary Economics, vol. 75(C), pp. 123-137.

Gersbach, H., Schetter, U., and Schneider, M., (2015). "How Much Science? The $5 \mathrm{Ws}$ (and $1 \mathrm{H}$ ) of Investing in Basic Research," CEPR Discussion Papers 10482.

Grossman, G.M. and Helpman, E. (1991), "Quality Ladders in the Theory of Growth", Review of Economic Studies 58, pp. 43-61;

Howitt, Peter (2013). "From Curiosity to Wealth Creation: How University Research Can Boost Economic Growth", Commentary, C.D. Howe Institute, June.

Jones, C. and J. Williams (1998), "Measuring the Social Return to R\&D", Quarterly Journal of Economics, November 1998, Vol. 113, pp. 1119-1135.

Jones, C. and J. Williams (2000), "Too Much of a Good Thing? The Economics of Investment in R\&D", Journal of Economic Growth, March 2000, Vol. 5, No. 1, pp. 65-85.

Nelson, R., (2006), "Reflections on 'The Simple Economics of Basic Scientific Research': Looking Back and Looking Forward", Industrial and Corporate Change, v. 15, iss. 6, pp. 903-17. 
Scotchmer, S. (2004), Innovation and Incentives, MIT Press, Cambridge, Ma.

Spinesi, L., (2012), "Heterogeneous Academic-Industry Knowledge Linkage, Heterogeneous IPR, and Growth", Journal of Public Economic Theory, pp. 67-98.

Spinesi, L. (2013), "Academic and industrial R\&D: are they always complementary? A theoretical approach", Oxford Economic Papers, vol. 65(1), January, pp. 147-172. 